\title{
Classificação climática para o estado de Minas Gerais segundo as zonas de vida de Holdridge
}

\author{
Heitor Renan Ferreira ${ }^{\mathrm{a}^{*}}$, Andressa Tres ${ }^{\mathrm{a}}$, Alexandre França Tetto ${ }^{\mathrm{a}}$, Ronaldo Viana Soares ${ }^{\mathrm{a}}$, \\ William Thomaz Wendling ${ }^{\mathrm{a}}$, Antonio Carlos Batista ${ }^{\mathrm{a}}$ \\ ${ }^{\text {a } U n i v e r s i d a d e ~ F e d e r a l ~ d o ~ P a r a n a ́, ~ B r a s i l ~}$ \\ *Autor correspondente (bmheitorf@gmail.com)
}

\section{N F O}

\section{Keywords}

climate

biotemperature

rainfall

Palavras-chaves

clima biotemperatura precipitação

\begin{abstract}
A B S T R A C T
Climate classification for Minas Gerais state according to the Holdridge life zones.

The climate exerts a notable influence on the processes of the planet, whether in the daily life of people, in the distribution of plant and animal species or in agroforestry activities. Numerous classifications were proposed to determine the climate of a region. In 1947, Holdridge proposed the life zones classification using biotemperature, rainfall, altitude and latitude data. Thus, the aim of this work was to classify the state of Minas Gerais according to the Holdridge life zones, as well as compare it with Köppen's climate classification and the distribution of vegetation in the state. For this, a historical series of 25 years meteorological records data were used, in addition to the classification of Köppen and the vegetation classes of the state. Nine life zones were found and the most representative were premontane tropical moist forest $(45.1 \%)$, subtropical moist forest $(19.1 \%)$ and premontane tropical dry forest $(10.8 \%)$. When comparing the Köppen's climate classification and Holdridge life zones, it was found that the classifications that obtained the highest value relation to premontane tropical moist forest were Cwa (58.2\%) and Cwb $(50.3 \%)$. In comparison with the vegetation classes it was verified that premontane tropical moist forest had a greater relation with savanna (67.3\%) and savanna/seasonal forest $(72.3 \%)$. Based on the results obtained, it was observed that Holdridge life zones showed a good relation in the comparisons with Köppen and the vegetation map and is therefore suitable for classification of the state of Minas Gerais.
\end{abstract}

\section{R E S U M O}

O clima exerce notória influência nos processos do planeta, seja no cotidiano das pessoas, na distribuição de espécies vegetais e animais ou nas atividades agroflorestais. Inúmeras classificações foram propostas objetivando determinar o clima de uma região. Em 1947, Holdridge propôs uma classificação utilizando como variáveis a biotemperatura, a precipitação e a altitude, nomeando as suas classes como zonas de vida. Assim, o presente trabalho teve como objetivo classificar o estado de Minas Gerais de acordo com as zonas de vida de Holdridge, bem como comparar com a classificação proposta por Köppen e com a distribuição da vegetação no estado. Para isso utilizou-se uma base de dados meteorológicos, de 25 anos de registros, além da classificação de Köppen e das classes vegetacionais do estado. Foram encontradas nove zonas de vida, sendo as mais representativas: floresta úmida tropical premontana $(45,1 \%)$, floresta úmida subtropical basal $(19,1 \%)$ e floresta seca tropical premontana (10,8\%). Ao comparar a classificação de Köppen e Holdridge, verificou-se que as classificações que obtiveram o maior valor de relação com a floresta úmida tropical premontana foram as do tipo Cwa $(58,2 \%)$ e Cwb $(50,3 \%)$. Na comparação com as classes vegetacionais foi verificado que a zona de vida floresta úmida tropical premontana teve maior relação com savana $(67,3 \%)$ e savana/floresta estacional $(72,3 \%)$. Com base nos resultados obtidos observou-se que a classificação de Holdridge apresentou boa relação nas comparações com Köppen e o mapa de vegetação, sendo assim adequado para classificação climática do estado de Minas Gerais. 


\section{INTRODUÇÃO}

O clima, desde o início da evolução terrestre, influencia diretamente e indiretamente no desenvolvimento dos reinos vegetal e animal. Devido à notória importância do clima para os processos vitais na terra, foram propostas diversas classificações objetivando, por meio de dados de variáveis (temperatura, precipitação e biotemperatura), determinar os diferentes tipos de clima presentes no planeta. Porém, devido a heterogeneidade do sistema climático da Terra, a construção de um modelo físico-matemático, que considere todos os fatores que influenciam o clima, é um desafio para a ciência (Vianello e Alves, 1991).

O clima é o produto da ação combinatória de fatores meteorológicos de um determinado momento (Walter, 1986), não podendo ser compreendido isoladamente sem estar relacionado a outras variáveis. Assim, Holdridge propôs em 1947 uma classificação que procurasse realizar divisões harmônicas da biosfera (Sawyer Júnior e Lindsey, 1964), baseando-se na organização dos dados climáticos e na compreensão das variações do clima no mundo (Ayoade, 2010).

Dentre outras utilidades, as classificações climáticas caracterizam determinada região para inúmeros objetivos, como para a obtenção do sucesso no zoneamento agrícola e florestal, com vistas à uma melhor produtividade qualitativa e quantitativa.

A classificação de Holdridge se norteia na premissa que a heterogeneidade vegetativa reflete os efeitos dos fatores climáticos sobre esta (Tuhkanen, 1980) e utiliza a biotemperatura média anual, a precipitação anual e a taxa de evapotranspiração anual para realização de associações juntamente com as formações vegetais (Hincapié e Caicedo, 2013).

Soares et al. (2015) consideram a classificação de Holdridge como um engenhoso sistema de classificação que se baseia em parâmetros que afetam sensivelmente a vegetação, e que ao se comparar com a classificação de Köppen, a classificação de Holdridge se sobressai por uma característica mais ecológica relacionada à biotemperatura, enquanto Köppen apresenta uma caracterização mais geográfica.

O estado de Minas Gerais é uma potência florestal no Brasil e apresenta a maior área plantada de eucalipto, correspondendo no ano de 2016 a 1.390.032 hectares $(24,5 \%)$ de um total de 5.673.783 hectares existentes no país (Indústria Brasileira de Árvores, 2017). Além disso apresenta a produção de diversos cultivos agrícolas, o que evidencia o interesse na classificação de seu território para as áreas existentes e futuramente exploradas e/ou modificadas.
Assim, este trabalho teve como objetivo classificar os municípios do estado de Minas Gerais de acordo com o sistema de zonas de vida proposto por Holdridge, sendo posteriormente comparado com o mapa de vegetação e da classificação climática de Köppen para o respectivo estado.

\section{MATERIAL E MÉTODOS}

\section{Área de estudo}

A área de estudo compreende o estado de Minas Gerais, localizado entre os paralelos $14^{\circ} 13^{\prime} 58^{\prime \prime}$ e $22^{\circ} 55^{\prime} 20^{\prime \prime}$ de latitude sul e os meridianos de $39^{\circ}$ $51^{\prime} 23^{\prime \prime}$ e $51^{\circ} 02^{\prime} 44^{\prime \prime}$ de longitude oeste de Greenwich, pertencente à região sudeste do Brasil (IBGE, 2011), apresentando uma área de $586.520,73 \mathrm{~km}^{2}$ (IBGE, 2017). Possui uma precipitação média anual de 1.394,04 mm (Alvares et al., 2013) e, de acordo com Reboita et al. (2015), existe um gradiente de temperatura sul-noroeste, onde no sul a média de temperatura mínima anual apresenta $14{ }^{\circ} \mathrm{C}$, a média $21^{\circ} \mathrm{C}$ e a máxima $27^{\circ} \mathrm{C}$, enquanto que no noroeste do estado os valores são de 19, 25 e $31^{\circ} \mathrm{C}$, respectivamente.

O estado é composto por 853 municípios e, de acordo com Alvares et al. (2013), apresenta 6 tipos climáticos na classificação de Köppen, sendo eles: Aw (clima tropical com inverno seco), As (clima tropical com verão seco), Cwa (clima úmido subtropical com inverno seco e verão quente), $\mathrm{Cwb}$ (clima úmido subtropical com inverno seco e verão temperado), Cfa (clima úmido subtropical com verão quente) e Cfb (clima úmido subtropical com verão temperado).

\section{Obtenção dos dados}

Para elaboração do trabalho foi utilizada a base de dados disponibilizada por Alvares et al. (2013), que inclui dados de altitude média (Figura 1A), classificação de Köppen (Figura 1B) e dados de precipitação anual (Figura 1C) para cada município de Minas Gerais. O shape de vegetação utilizado foi disponibilizado pelo IBGE e para diminuir as classes de vegetação, simplificando as comparações, seguiu-se o reagrupamento proposto por Tres (2016), o qual originou o mapa de vegetação da figura 1D.

Os dados de altitude média dos municípios foram obtidos por meio de um Modelo de Elevação Digital (MDE). Os dados meteorológicos foram obtidos através das seguintes fontes: o Instituto Nacional de Meteorologia (INMET), o Departamento Nacional de Obras Contra as Secas (DNOCS) e a 
Organização das Nações Unidas para a Alimentação e Agricultura (FAO/ONU). Esta base de dados foi composta por 25 anos de registros, coletada en- tre os anos de 1950 e 1990 , de 2.950 estações meteorológicas para os dados de precipitação e 2.400 estações para os dados referentes a temperatura (Alvares et al., 2013).

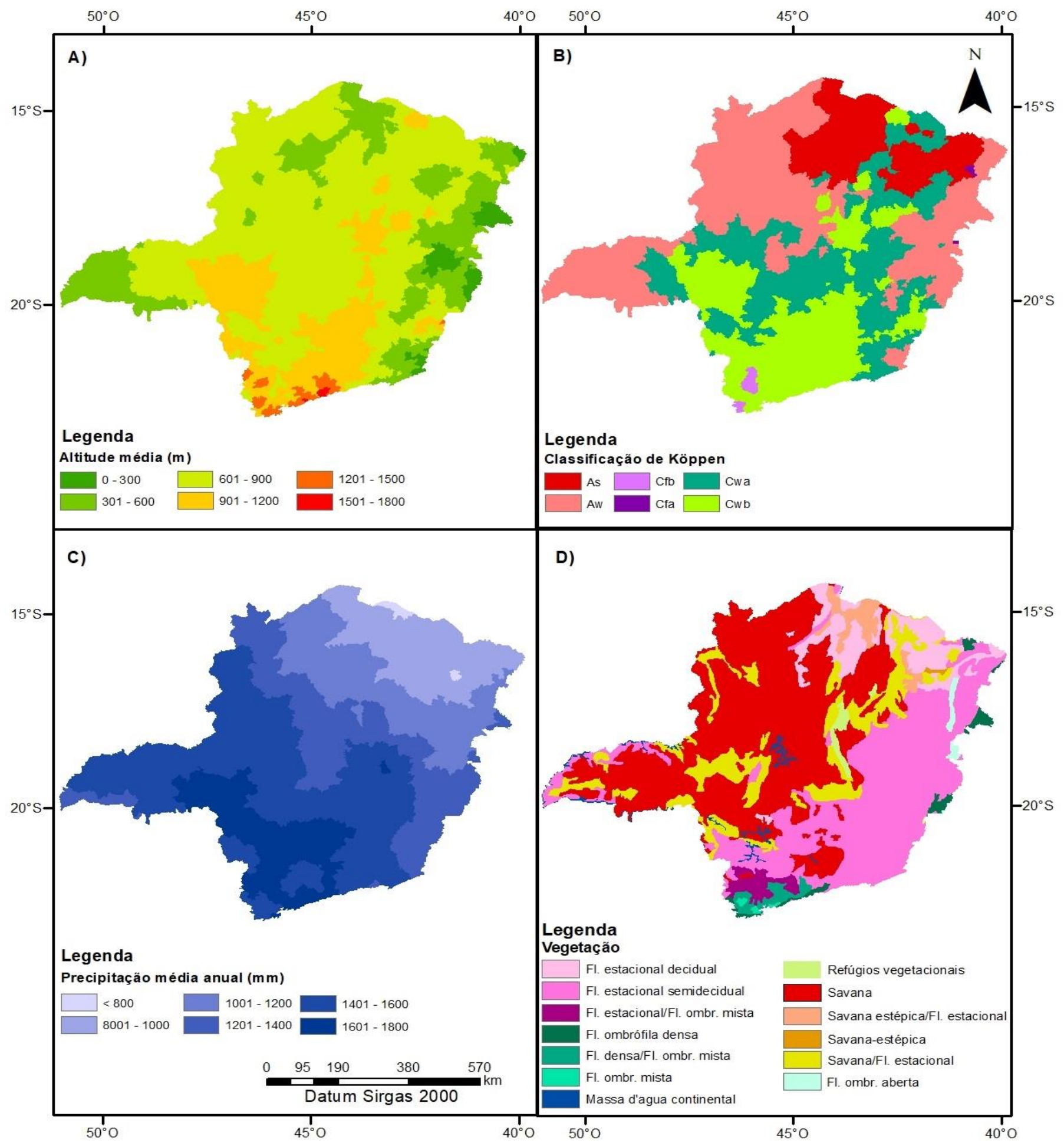

Fontes: (A), (B) e (C): Alvares et al. (2013), adaptado pelos autores (2019) e (D): IBGE (2006) adaptado pelos autores (2019) Nota: Fl.: Floresta; Ombr.: Ombrófila

Figura 1 - A) Mapa de altitudes médias dos municípios de Minas Gerais; B) Mapa da classificação de Köppen; C) Mapa de precipitação média anual; e D) Mapa de vegetação. 


\section{Classificação de Holdridge}

Para a realização da classificação de Holdridge foram utilizados os cálculos da biotemperatura e os valores de precipitação anual.

Para determinação da biotemperatura, que por definição é o intervalo de temperatura no qual ocorre o efetivo crescimento das plantas, foi considerado o intervalo que compreende as temperaturas de 0 a $30^{\circ} \mathrm{C}$, conforme descrito por Soares et al. (2015). Seguindo a classificação de Holdridge (1967), todas as temperaturas médias mensais inferiores a $0{ }^{\circ} \mathrm{C}$ devem ser descartadas e as superiores a $24^{\circ} \mathrm{C}$ devem ser corrigidas, para eliminar as temperaturas maiores que $30{ }^{\circ} \mathrm{C}$ ocorridas durante o mês, mediante a seguinte equação:
Onde:

$$
T_{\text {bio }}=T-\left[\frac{3 l}{100}(T-24)^{2}\right]
$$

$T_{\text {bio }}=$ biotemperatura do mês, em ${ }^{\circ} \mathrm{C}$;

$T=$ temperatura média do mês, em ${ }^{\circ} \mathrm{C}$;

$l=$ latitude do lugar, em graus decimais.

Após determinação das biotemperaturas mensais, foi estimada a biotemperatura média anual de cada município mediante a soma de todas as biotemperaturas mensais com valores acima de $0{ }^{\circ} \mathrm{C}$, dividindo-as por 12 (número de meses do ano).

Com a obtenção da biotemperatura média anual e precipitação, foi realizado a determinação das zonas de vida do sistema de Holdridge (Figura 2).

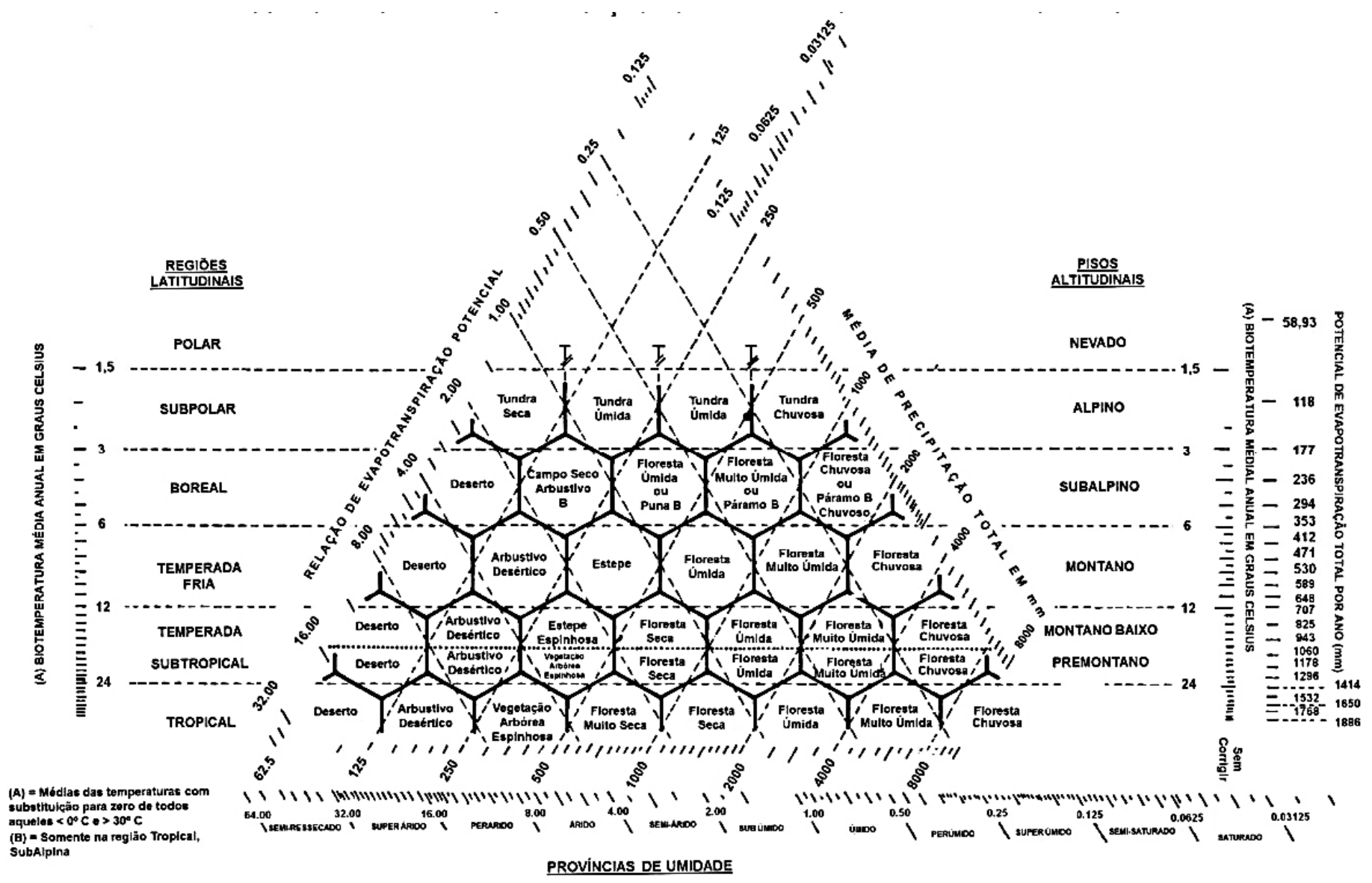

Fonte: Holdridge (2000), adaptado por Soares et al. (2015)

Figura 2 - Diagrama para determinação das zonas de vida de Holdridge.

As linhas horizontais representam a biotemperatura média anual, enquanto as linhas diagonais representam a precipitação anual e a evapotranspiração potencial. Realizando o cruzamento das linhas da biotemperatura média anual e da precipitação média anual, foi obtida a zona de vida de cada município, sendo estas delimitadas por hexágonos. As áreas de transição estão delimitadas através dos triângulos equiláteros. $\mathrm{O}$ passo subsequente para a classificação foi a correção da biotemperatura para o nível do mar (usando gradiente adiabático médio de $0,6{ }^{\circ} \mathrm{C} / 100 \mathrm{~m}$ ) para posterior determinação da região latitudinal e do piso altitudinal, completando assim a classificação proposta por Holdridge (1967) (Figura 3). 


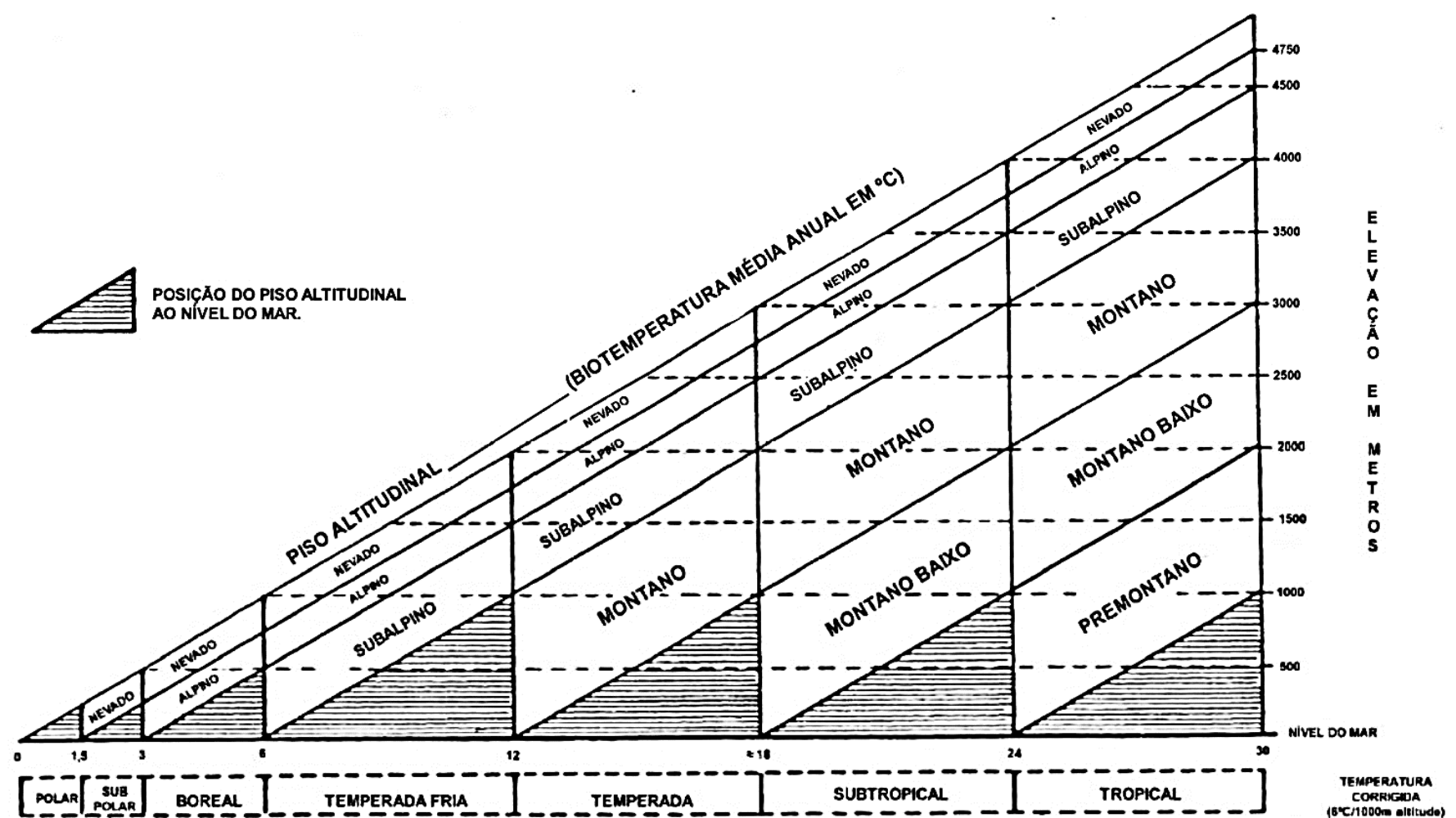

REGIOES LATITUDINAIS

(BLTEMPERATURA ANUAL MÉdIA AO NIVEL DO MAR EM ${ }^{\circ} \mathrm{C}$ )

Fonte: Soares et al. (2015)

Figura 3 - Diagrama de pisos altitudinais de Holdridge.

\section{Processamento e análise dos dados}

O processamento dos dados se deu por meio de um programa de computação desenvolvido no software FoxPro e, após a classificação climática de cada município do estado de Minas Gerais, as informações foram processadas em software de geoprocessamento.

Ao fim, foram realizadas comparações das zonas de vida de Holdridge para o estado com a classificação de Köppen, elaborada por Alvares et al. (2013), e com o mapa de vegetação do IBGE (2006) reagrupado conforme proposto por Tres (2016). A comparação entre a classificação de Holdridge e Köppen foi realizada mediante a área ocupada por cada município e sua classificação, enquanto a comparação entre a classificação de Holdridge e o mapa de vegetação do IBGE, foi realizada por meio da utilização da ferramenta de análise espacial "Zonal Histogram".

\section{RESULTADOS E DISCUSSÃO}

A biotemperatura média anual máxima e mínima no estado de Minas Gerais foi de 14,2 a $23,5{ }^{\circ} \mathrm{C}$ (Figura 4). Foi observado que há uma influência di- reta da altitude média do município na biotemperatura deste, sendo que no geral aqueles com maiores altitudes apresentaram menor valor de biotemperatura, destacando Itamonte (1.592 $\mathrm{m}$ de altitude), Marmelópolis $(1.570 \mathrm{~m}$ de altitude) e Alagoa (1.505 $\mathrm{m}$ de altitude), que possuem respectivamente as biotemperaturas mais baixas de 14,2, 14,4 e $14,7^{\circ} \mathrm{C}$ e estão localizados na região sul de minas, na Bacia do Rio Grande.

Com relação à biotemperatura, $77.977,02 \mathrm{~km}^{2} \mathrm{da}$ área do estado $(13,3 \%)$ apresentou um valor superior a $22,0{ }^{\circ} \mathrm{C}$, sendo que $62.620,93 \mathrm{~km}^{2}$ desta área $(80,3 \%)$ está presente em altitudes de até $600 \mathrm{~m}$, demonstrando a relação da baixa altitude com as maiores biotemperaturas no estado. Estas regiões são representadas pelo: Triângulo Mineiro ao oeste, divisa com os estados de Goiás, Mato Grosso do Sul e São Paulo; noroeste de Minas, divisa com Goiás, Distrito Federal e Bahia; norte de Minas, divisa com a Bahia; Jequitinhonha/Mucuri e Rio Doce ao leste, divisas com os estados da Bahia e Espírito Santo ao leste.

Houve duas classificações para a região latitudinal em que Minas Gerais está inserida, sendo elas tropical e subtropical (Figura 5), presentes respectivamente em 71,7 e 28,3\% dos municípios. 


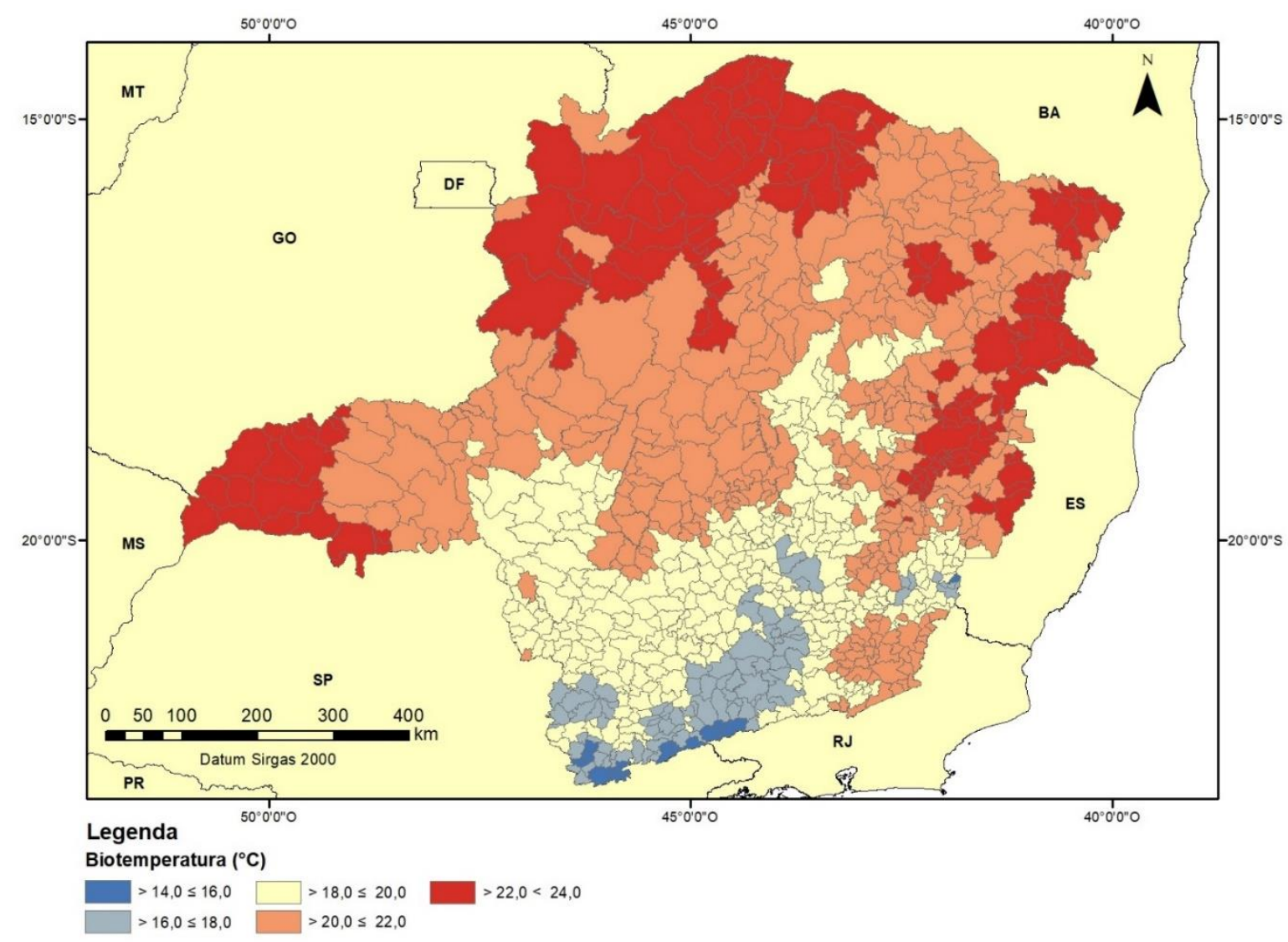

Figura 4 - Mapa de biotemperaturas médias anuais.

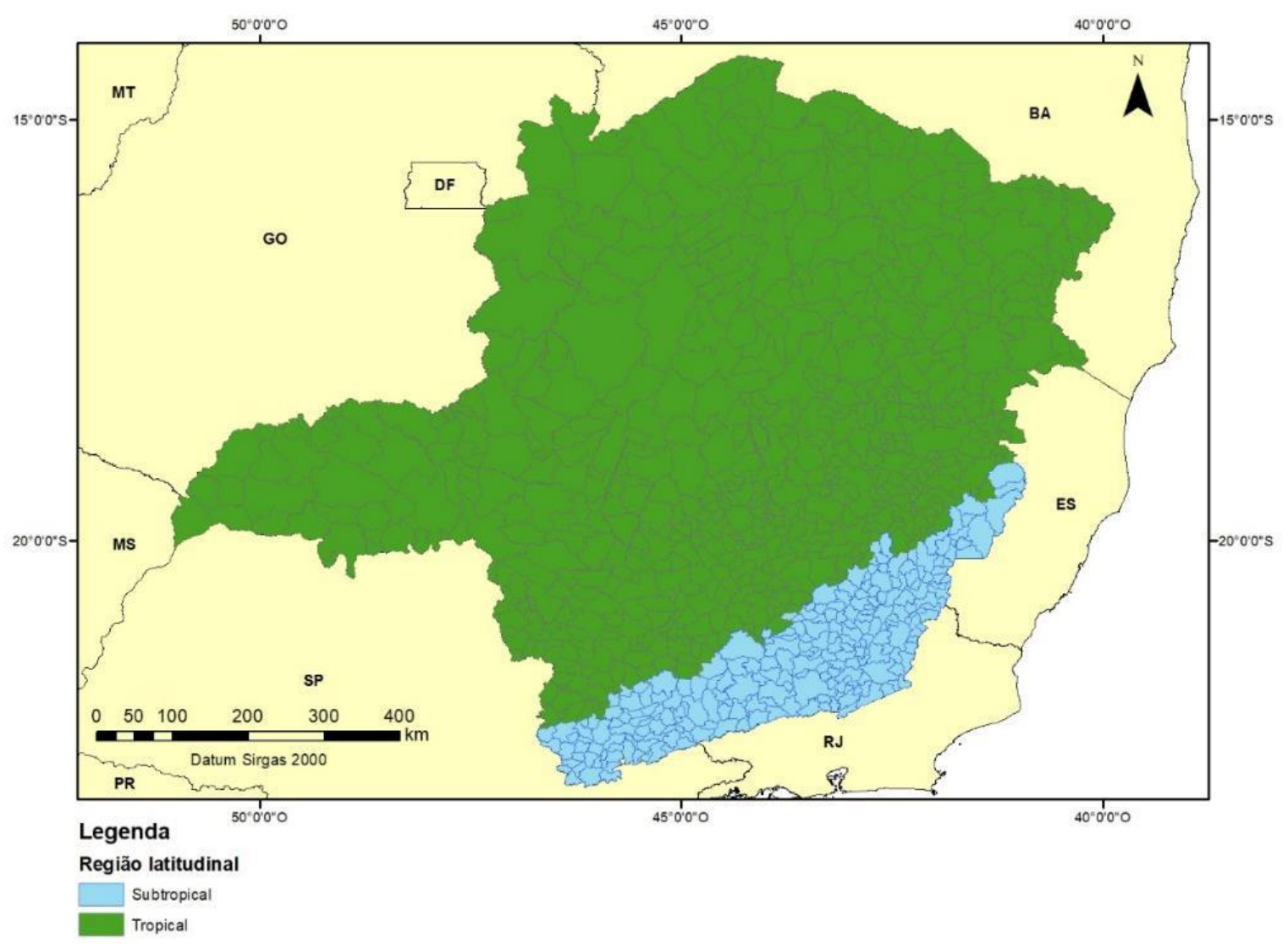

Figura 5 - Mapa das classificações latitudinais de Minas Gerais. 
Eloi (2001), ao aplicar metodologia proposta por Holdridge mediante utilização de uma tabela com classes de latitude, observou que Minas Gerais está presente em sua totalidade na região latitudinal subtropical, diferenciando da classificação realizada por este trabalho, uma vez que a base de dados meteorológicos e o período analisado foram divergentes entre os trabalhos.

Quanto ao piso altitudinal, foram encontradas três classificações para o estado de Minas Gerais, sendo basal (19,0\% dos municípios), premontana $(69,2 \%)$ e montana baixa $(11,8 \%)$ (Figura 6$)$.

O piso basal está presente em sua maioria na bacia hidrográfica Paraíba do Sul, localizada ao sudeste de Minas Gerais, nas divisas com os estados de Rio de Janeiro e Espírito Santo, compreendendo a região da Mata. O piso altitudinal montano baixo está inserido em sua maioria na bacia do Rio Grande e a serra da Mantiqueira compõe parte de sua área, nas divisas com Rio de Janeiro e São Paulo. O piso premontano, que ocupa $69,2 \%$ do estado, esteve presente em parte de todas as regiões de Minas Gerais.

Para o estado de Minas Gerais foram obtidas nove zonas de vida conforme apresentado na figura 7.

A zona de vida mais representativa para o estado

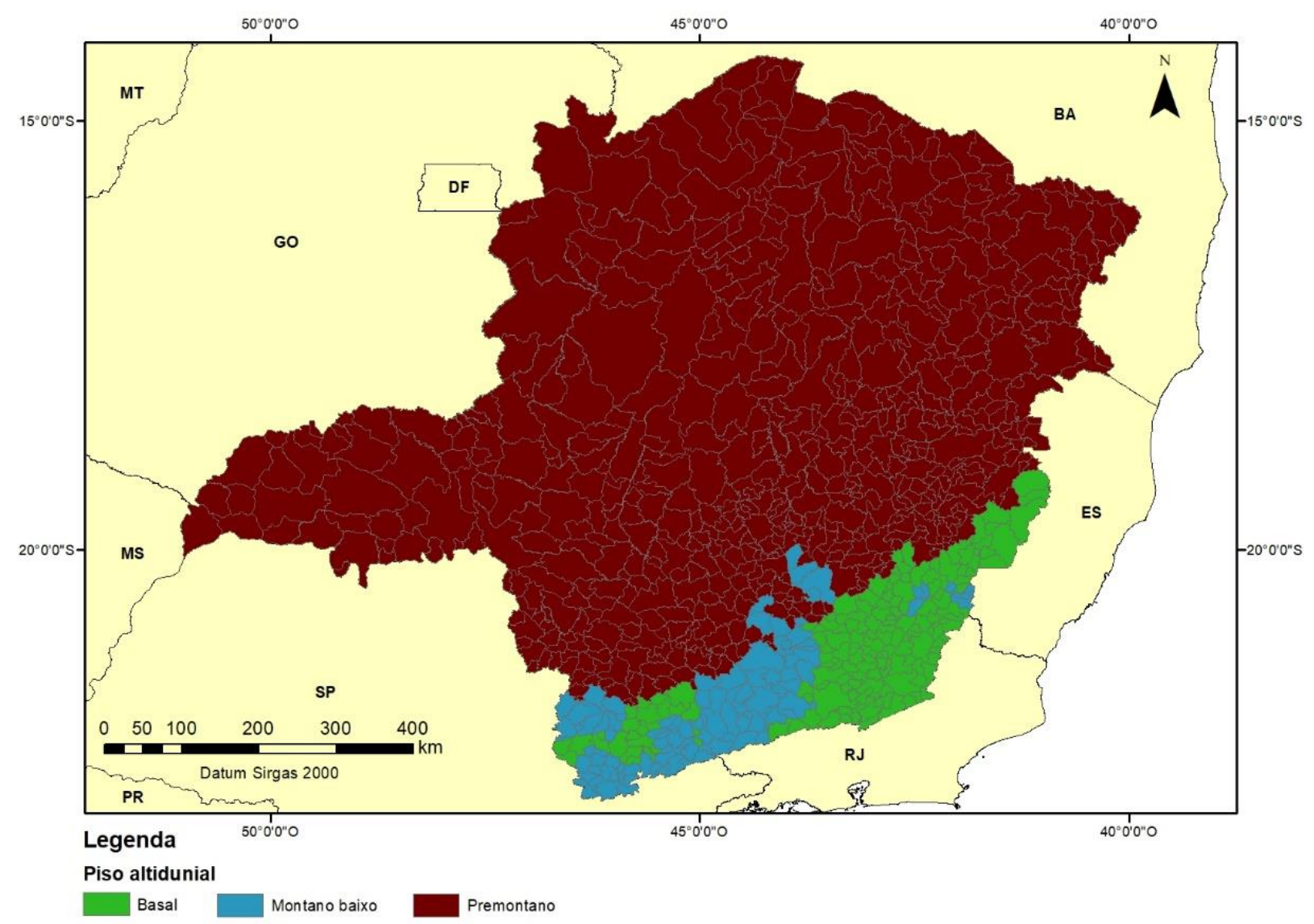

de Minas Gerais foi a floresta úmida tropical premontana, que está presente em 394 municípios, totalizando uma área de $264.282,77 \mathrm{~km}^{2}$, o que representa $45,1 \%$ da área do estado. Na sequência ficaram: floresta úmida subtropical basal $(19,1 \%)$, floresta seca tropical premontana $(10,8 \%)$, floresta úmida subtropical montana baixa $(10,6 \%)$ e floresta úmida tropical montana baixa $(2,6 \%)$, totalizando uma área total de $253.157,15 \mathrm{~km}^{2}(43,1 \%)$.

As zonas de transição que compreenderam a classificação floresta úmida/seca tropical premontana, floresta seca/úmida tropical premontana, floresta úmida/seca subtropical basal e floresta úmida/muito úmida subtropical montana baixa ocuparam 6,1, 5,0,0,6 e 0,02\% da área de extensão do estado, respectivamente, totalizando $11,8 \%$ $\left(69.080,81 \mathrm{~km}^{2}\right)$.

$\mathrm{Na}$ espacialização das classificações de cada município, observou-se que na divisa com o estado da Bahia, compreendendo as regiões norte de Minas e Jequitinhonha/Mucuri, ao norte e nordeste do estado, houve a presença da zona de vida classificada como floresta seca tropical premontana, que ao ser comparada com o mapa de precipitação média anual, demonstra a relação entre a classificação de Holdridge e o déficit pluviométrico da região.

Figura 6 - Mapa das classificações atitudinais de Minas Gerais. 


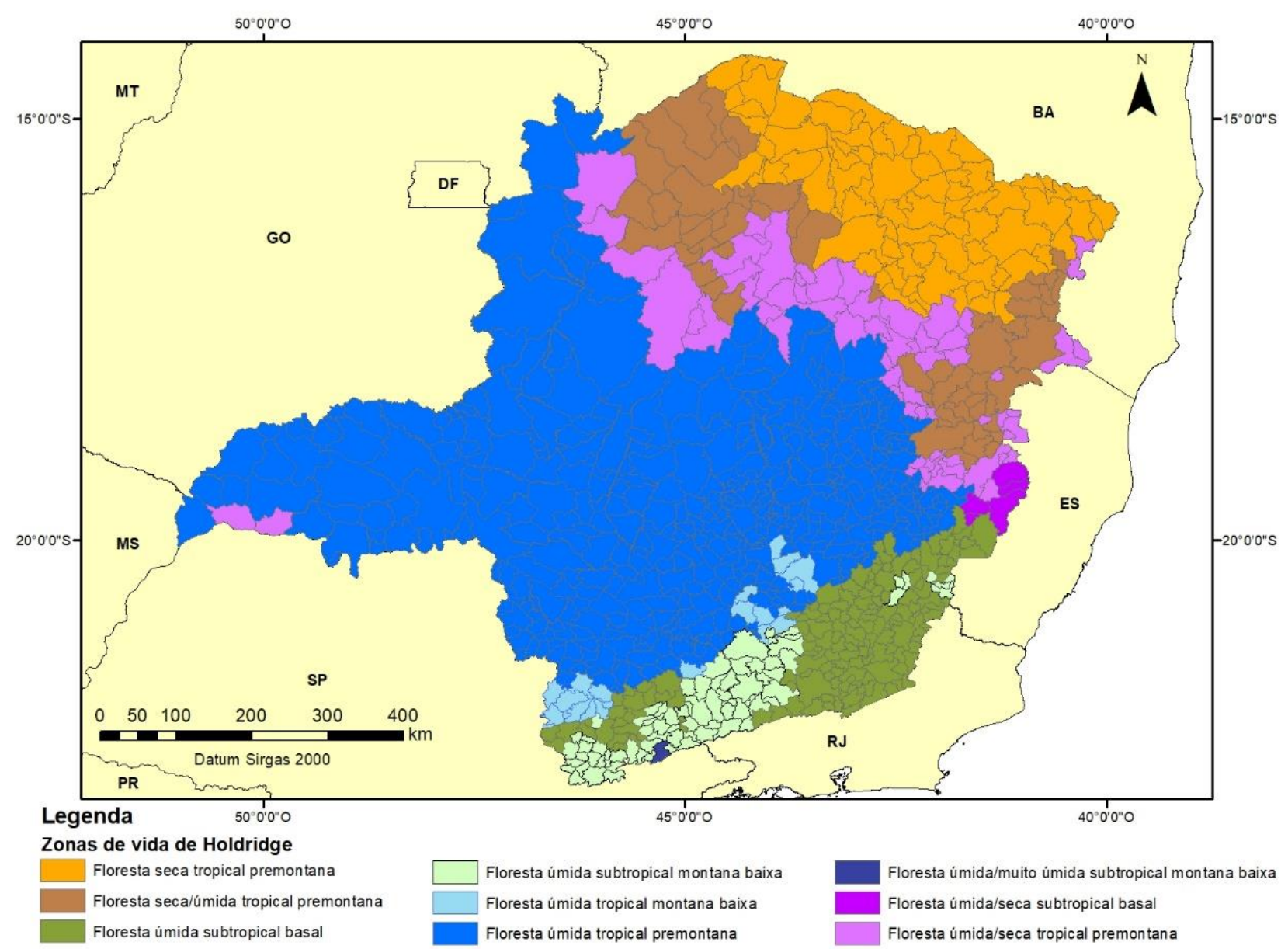

Figura 7 - Mapa de zonas de vida de Holdridge.

Parte da região sul do estado, onde está localizada a serra da Mantiqueira, teve sua classificação como floresta úmida subtropical montana baixa que, ao ser relacionada com o mapa de biotemperatura e de altitudes médias, apresentou valores maiores que $14 \mathrm{e}$ menores ou iguais a $16^{\circ} \mathrm{C}$ e as maiores altitudes do estado. A floresta úmida subtropical basal está contida em sua maioria na região da Mata.

A zona de vida floresta úmida tropical premontana, que englobou $45,1 \%$ do estado, esteve presente nas áreas onde a precipitação média anual foi superior a $1.000 \mathrm{~mm}$ e uma altitude média máxima de $1.200 \mathrm{~m}$.

Eloi (2001) verificou que o estado possui 10 zonas de vida e em sua totalidade florestas, mas também constatou que há algumas zonas muito secas, contrariando o que foi obtido no presente trabalho, visto que a série histórica utilizada foi diferente. Além disso, todas as zonas de vida foram classificadas com a região latitudinal subtropical devido a metodologia aplicada pelo mesmo.

Para o estado do Paraná, Milano et al. (1987) verificaram a ocorrência de sete zonas de vida, sendo que a floresta úmida temperada obteve a maior ocupação no estado. Nogueira et al. (1987) encontraram no estado de Santa Catarina quatro zonas de vida, obtendo também a classificação de floresta úmida temperada com maior representatividade no estado.

Carvalho et al. (2008), ao realizar a classificação climática de Thornthwaite para Minas Gerais, encontraram 8 classes, variando da classificação D (semiárido) no nordeste do estado, divisa com a Bahia, até a classificação A (super úmido) ao extremo sul do estado, divisa com São Paulo, corroborando com o presente trabalho acerca da característica umidade em questão e sua espacialização. A distribuição ainda englobou as classificações de úmido (B4, B3, B2 e B1), subúmido (C2) e subúmido seco (C1).

\section{Relação entre as classificações de Holdridge e Köppen}

A tabela 1 apresenta a comparação entre a classificação proposta por Holdridge e a classificação de Köppen. 
Tabela 1 - Zonas de vida de Holdridge em comparação a classificação de Köppen.

\begin{tabular}{lcccccc}
\hline \multirow{2}{*}{\multicolumn{1}{c}{ Zonas de vida de Holdridge }} & \multicolumn{5}{c}{ Classificação de Köppen (\%) } \\
\cline { 2 - 7 } & Aw & Cwa & Cwb & As & Cfb & Cfa \\
\hline Floresta úmida tropical premontana & 36,9 & 58,2 & 50,3 & - & - & - \\
Floresta úmida subtropical basal & 18,0 & 30,7 & 12,5 & - & 14,7 & - \\
Floresta seca/úmida tropical premontana & 17,9 & 0,4 & - & 16,6 & - & - \\
Floresta seca tropical premontana & 3,6 & 8,2 & 1,9 & 78,8 & - & 41,5 \\
Floresta úmida/seca subtropical basal & 3,2 & - & - & - & - & - \\
Floresta úmida subtropical montana baixa & - & - & 29,3 & - & 39,7 & - \\
Floresta úmida/seca tropical premontano & 20,4 & 2,5 & 1,1 & 4,6 & - & 58,5 \\
Floresta úmida tropical montana baixa & - & - & 4,8 & - & 45,6 & - \\
Floresta úmida/muito úmida subtropical montana baixa & - & - & 0,1 & - & - & - \\
\hline \multicolumn{1}{c}{ TOTAL } & 100,0 & 100,0 & 100,0 & 100,0 & 100,0 & 100,0 \\
\hline
\end{tabular}

Fonte: Alvares et al. (2013), IBGE (2017), adaptado pelos autores (2019)

Com relação à comparação entre a classificação de Köppen e Holdridge, verificou-se que as classificações que obtiveram o maior valor de relação com a floresta úmida tropical premontana foram as do tipo Cwa $(58,2 \%)$, Cwb (50,3\%) e Aw $(36,9 \%)$. Observou-se que o tipo climático Cwb, por se tratar de um clima úmido subtropical com inverno seco e verão temperado, também esteve presente com maior representatividade na floresta úmida subtropical montana baixa $(29,3 \%)$.

A classificação As obteve um índice de 78,8\% de relação com a classificação floresta seca tropical premontana, evidenciando que a região nordeste do estado de Minas Gerais, onde ambas classificações estão mais concentradas, apresenta um clima mais seco. Além disso, a classificação As não esteve relacionada diretamente junto as classificações exclusivas de florestas úmidas.
A classificação Cfb esteve presente em uma área de $12.731,57 \mathrm{~km}^{2}$ (2,2\% do estado), enquanto a classificação Cfa esteve presente em uma área de $4.504,44 \mathrm{~km}^{2}(0,8 \%)$, apresentando assim baixa representatividade em Minas Gerais. Por se tratar de uma classificação de clima úmido subtropical com verão temperado, a classificação $\mathrm{Cfb}$ esteve presente exclusivamente em zonas úmidas, enquanto a classificação $\mathrm{Cfa}$, caracterizada por clima úmido subtropical com verão quente, apresentou-se nas classificações envolvendo florestas secas.

\section{Relação entre a classificação de Holdridge e a vegetação}

A tabela 2 apresenta a disposição das classes de vegetação no estado de Minas Gerais e a tabela 3 a comparação entre as classes de vegetação com a classificação das zonas de vida de Holdridge.

Tabela 2 - Representatividade das classes de vegetação no estado de Minas Gerais.

\begin{tabular}{lcc}
\hline \multicolumn{1}{c}{ Classe de vegetação } & \% & $\mathbf{k m}^{\mathbf{2}}$ \\
\hline Savana & 41,5 & $243.646,01$ \\
Floresta estacional semidecidual & 30,2 & $176.944,50$ \\
Savana/floresta estacional & 11,8 & $69.379,89$ \\
Floresta estacional decidual & 7,3 & $42.667,77$ \\
Savana estépica/floresta estacional & 2,4 & $13.864,52$ \\
Floresta estacional/floresta ombrófila mista & 1,6 & $9.539,02$ \\
Floresta ombrófila densa & 1,3 & $7.662,73$ \\
Floresta ombrófila densa/floresta ombrófila mista & 1,2 & $7.032,52$ \\
Massa d'agua continental & 1,0 & $5.929,66$ \\
Refúgios vegetacionais & 0,8 & $4.869,77$ \\
Floresta ombrófila aberta & 0,6 & $3.236,96$ \\
Floresta ombrófila mista & 0,2 & $1.016,92$ \\
Savana estépica & 0,1 & 730,46 \\
\hline TOTAL & 100,0 & $586.520,73$ \\
\hline
\end{tabular}

Fonte: IBGE (2006), adaptado pelos autores (2019) 
Tabela 3 - Classes de vegetação em comparação a classificação de Holdridge.

CLASSES DE VEGETAÇÃO (\%)

$\begin{array}{llllllllllllll}\begin{array}{l}\text { Zonas de vida de } \\ \text { Holdridge }\end{array} & \text { FES } & \text { SA } & \text { SA/ } & \text { FOD } & \text { FOD/ } & \text { FOM } & \text { FE/ } & \text { FED } & \text { RV } & \begin{array}{c}\text { SA } \\ \text { Es./ }\end{array} & \text { FOA } & \begin{array}{l}\text { SA- } \\ \text { Es. }\end{array}\end{array}$

\begin{tabular}{|c|c|c|c|c|c|c|c|c|c|c|c|c|}
\hline $\begin{array}{l}\text { Floresta úmida tropi- } \\
\text { cal premontana }\end{array}$ & 43,6 & 67,3 & 72,3 & - & - & - & 8,4 & 1,5 & 71,5 & - & - & - \\
\hline $\begin{array}{l}\text { Floresta úmida sub- } \\
\text { tropical basal }\end{array}$ & 19,3 & - & - & 25,4 & 12,8 & - & 44,8 & - & 1,2 & - & 1,3 & - \\
\hline $\begin{array}{l}\text { Floresta seca/úmida } \\
\text { tropical premontana }\end{array}$ & 13,7 & 11,7 & 0,3 & 5,6 & - & - & - & 17,9 & - & 7,2 & 39,4 & - \\
\hline $\begin{array}{l}\text { Floresta seca tropical } \\
\text { premontana }\end{array}$ & 6,4 & 4,2 & 16,4 & 14,6 & - & - & - & 77,9 & - & 92,8 & 29,7 & 100,0 \\
\hline $\begin{array}{l}\text { Floresta úmida/seca } \\
\text { subtropical basal }\end{array}$ & 2,0 & - & - & 4,5 & - & - & - & - & - & - & - & - \\
\hline $\begin{array}{l}\text { Floresta úmida sub- } \\
\text { tropical montana } \\
\text { baixa }\end{array}$ & 3,7 & 2,6 & - & 24,1 & 84,1 & 97,2 & 18,9 & - & 0,9 & - & - & - \\
\hline $\begin{array}{l}\text { Floresta úmida/seca } \\
\text { tropical premontana }\end{array}$ & 8,5 & 13,4 & 11,0 & 23,4 & - & - & - & 2,7 & 26,4 & - & 29,6 & - \\
\hline $\begin{array}{l}\text { Floresta úmida tropi- } \\
\text { cal montana baixa }\end{array}$ & 2,8 & 0,8 & - & - & - & - & 27,9 & - & - & - & - & - \\
\hline $\begin{array}{l}\text { Floresta úmida/muito } \\
\text { úmida subtropical } \\
\text { montana baixa }\end{array}$ & - & - & - & 2,4 & 3,1 & 2,8 & - & - & - & - & - & - \\
\hline $\begin{array}{l}\text { TOTAL } \\
\end{array}$ & 100,0 & 100,0 & 100,0 & 100,0 & 100,0 & 100,0 & 100,0 & 100,0 & 100,0 & 100,0 & 100,0 & 100,0 \\
\hline
\end{tabular}

Fonte: Alvares et al. (2013), IBGE (2006 e 2012), Tres (2016), adaptado pelos autores (2019)

NOTA: FES: Floresta Estacional Semidecidual; SA: Savana; FE: Floresta Estacional; FOD: Floresta Ombrófila Densa; FOM: Floresta Ombrófila Mista; FED: Floresta Estacional Decidual; ES: Estépica; FOA: Floresta Ombrófila Aberta; RV: Refúgio Vegetacional

As classes de vegetação floresta estacional semidecidual $(43,6 \%)$, Savana $(67,3 \%)$, savana/floresta estacional $(72,3 \%)$ e refúgios vegetacionais $(71,5 \%)$ obtiveram maior representatividade junto à zona de vida floresta úmida tropical premontana, visto que a mesma foi responsável por maior abrangência da área do estado de Minas Gerais.

A área de transição entre a savana estépica e a floresta estacional apresentou uma relação de $92,8 \%$ com a zona de vida floresta seca tropical premontana, enquanto a floresta estacional decidual apresentou 77,9\% de relação. Ainda na referida zona de vida, a vegetação tipo savana-estépica esteve presente em $100 \%$, porém apresentou uma representatividade de $0,1 \%$ da área do estado. Com esses resultados observou-se uma relação entre uma floresta seca com uma vegetação menos exigente de recursos hídricos, sendo mais adaptada a altas temperaturas.

A floresta ombrófila mista esteve presente em $97,2 \%$ da zona de vida floresta úmida subtropical montana baixa, seguido pela transição entre a floresta ombrófila densa e a floresta ombrófila mista, que também estiveram presentes em $84,1 \%$ dos casos na respectiva zona de vida.

\section{CONCLUSÃO}

Com base nos resultados obtidos, foi possível concluir que o estado de Minas Gerais possui nove zonas de vida de acordo com a classificação das zonas de vida de Holdridge, apresentando quatro destas como zonas de transição. Observou-se ainda que houve boa correlação entre a classificação de Köppen e a de Holdridge, visto que algumas classificações obtiveram uma alta porcentagem de relação entre elas. No que se refere à comparação entre as classes de vegetação e a classificação de Holdridge, também foi observado relação entre algumas classes vegetacionais e as classificações de zonas de vida, evidenciando a adaptação da vegetação a um determinado clima. Por fim, devido à correspondência tanto com a classificação de Köppen quanto ao mapa vegetacional, se conclui que o sistema de classificação em zonas de vida de Holdridge se mostrou eficiente para o estado de Minas Gerais. 


\section{REFERÊNCIAS BIBLIOGRÁFICAS}

ALVARES, C.A.; STAPE, J.L.; SENTELHAS, P.C.; GONÇALVES, J.L.M.; SPAROVEK, G. Köppen's climate classification map for Brazil. Meteorologische Zeitschrift, v. 22, n. 6, p. $711-728,2013$. https://doi.org/10.1127/09412948/2013/0507

AYOADE, J.O. Introdução à climatologia para os trópicos. 14. ed. Rio de Janeiro: Bertrand Brasil, 2010. 350 p.

CARVALHO, L.G.; OLIVEIRA, M.S.; ALVES, M.C.; VIANELLO, R.L.; SEDIYAMA, G.C.; CASTRO NETO, P.; DANTAS, A.A.A. Clima. In: Scolforo, J.R.S.; Oliveira, A.D.; Carvalho, L.M.T. Zoneamento ecológico-econômico do estado de Minas Gerais: componentes geofísico e biótico. Lavras: Editora UFLA, 2008. p.89-101.

ELOI, C.M.A. Enquadramento das 'zonas de vida' de Holdridge na classificação climática de Minas Gerais. Ano de obtenção: 2001. 71p. Tese (Magister Scientiae) - Universidade Federal de Viçosa, Viçosa.

HINCAPIÉ, J.C.A.; CAICEDO, J.D.P. El cambio climático y la distribución espacial de las formaciones vegetales em Colombia. Colombia Forestal, Bogotá, v.16, n.2, p.171$185,2013$.

HOLDRIDGE, L.R. Life zone ecology. San José, Costa Rica: Tropical Science Center, 1967. 124p.

HOLDRIDGE, L.R. Ecologia basada em zonas de vida. San José, Costa Rica: Instituto Interamericano de Cooperación para la Agricultura, 2000.

INDÚSTRIA BRASILEIRA DE ÁRVORES (IBA). Relatório 2017. São Paulo, 2017. 80p.

INSTITUTO BRASILEIRO DE GEOGRAFIA E ESTATÍSTICA (IBGE). Shape de vegetação. 2006. Disponível em: <ftp://geoftp.ibge.gov.br/mapas_tematicos/mapas_murais/shapes/vegetacao/>. Acesso em: 20 mar. 2016.

INSTITUTO BRASILEIRO DE GEOGRAFIA E ESTATÍSTICA (IBGE). Anuário estatístico do Brasil. Rio de Janeiro, v. 71, 2011. 474p.

INSTITUTO BRASILEIRO DE GEOGRAFIA E ESTATÍSTICA (IBGE). Manuais técnicos em geociências: manual técnico de vegetação brasileira. Rio de Janeiro, 2. ed., 2012. 171p.

INSTITUTO BRASILEIRO DE GEOGRAFIA E ESTATÍSTICA (IBGE). Área da unidade territorial. Rio de Janeiro: IBGE, 2017. Disponível em: <https://cidades.ibge.gov.br/brasil/mg>. Acesso em: 24 mar. 2018.

MILANO, M.S.; BRASSIOLO, M.M.; SOARES, R.V. Zoneamento ecológico experimental do estado do Paraná segundo o sistema de zonas de vida de Holdridge. Floresta, Curitiba, v.17, n.12, p.65-72, 1987.

http://dx.doi.org/10.5380/rf.v17i12.6371

NOGUEIRA, A.C.; KUNIYOSHI, Y.S.; SOARES, R.V. Zonas de vida para o estado de Santa Catarina segundo a classificação das formações vegetais de Holdridge. Floresta, Curitiba, v.17, n.12, p. 103-112, 1987. http://dx.doi.org/10.5380/rf.v17i12.6372

REBOITA, M.; RODRIGUES, M.; SILVA, L.; ALVES, M. Aspectos climáticos do estado de Minas Gerais. Revista
Brasileira de Climatologia, v.17, p.206-226, 2015. http://dx.doi.org/10.5380/abclima.v17i0.41493

SAWYER JÚNIOR, J.O; LINDSEY, A.A. The Holdridge bioclimatic formations of eastern and central United States. Proceedings of the Indiana Academy of Science, n.73, p.105-112, 1964.

SOARES, R.V.; BATISTA, A.C.; TETTO, A.F. Meteorologia e climatologia florestal. Curitiba: Universidade Federal do Paraná, 2015. 215p.

TRES, A. Classificação climática para o Brasil segundo as zonas de vida de Holdridge. Ano de obtenção: 2016. 90p. Dissertação (Mestrado em Engenharia Florestal) - Universidade Federal do Paraná, Curitiba.

TRES, A.; TETTO, A.F.; SOARES, R.V.; WENDLING, W.T.; MENGATTO, A.P.R. Classificação do estado de Mato Grosso segundo sistema de zonas de vida de Holdridge. Enciclopédia Biosfera, Goiânia, v.13, n.23, p.329-343, 2016. https://doi.org/10.18677/Enciclopedia_Biosfera_2016_029

TUHKANEN, S. Climatic parameters and indices in plant geography. Acta Phytogeographica Suecica, Uppsala, n.67, p.1-105, 1980.

VIANELLO, R.L.; ALVES, A.R. Meteorologia básica e aplicações. Viçosa, 1991. 449p.

WALTER, H. Vegetação e zonas climáticas. São Paulo: Editora Pedagógica e Universitária, 1986. 326p. 